\title{
ANÁLISIS DOGMÁTICO DEL TIPO PENAL DE FRAUDE PROCESAL DESDE EL PUNTO DE VISTA DE SU CONTENIDO Y SU DESARROLLO JURISPRUDENCIAL EN LA CORTE SUPREMA DE JUSTICIA*
}

\author{
Rodolfo Mantilla Jácome* \\ Carolina Bayona Rangel ${ }^{* *}$ \\ Carlos Mario Frías Rubio \\ Recibido: Marzo 7 de 2016 \\ Aprobado: Junio 7 de 2016
}

\begin{abstract}
RESUMEN
Corresponde al artículo de investigación que se pregunta por las características dogmáticas del tipo penal de fraude procesal y su desarrollo ante la Sala Penal de la Corte Suprema de Justicia, visto desde la perspectiva del Derecho Penal como garantía de todos los ciudadanos. Se hallan las características teóricas de este tipo penal así como un desarrollo de reglas jurisprudenciales a las que se cuestiona por las garantías emanadas del principio de tipicidad.
\end{abstract}

Palabras clave: Fraude procesal, tipicidad, prescripción, delitos de ejecución permanente, delitos de resultado.

* Producto final del proyecto de investigación "El tipo penal de fraude procesal" desarrollado por Rodolfo Mantilla Jácome en calidad de investigador principal, en calidad de co-investigadores, Carolina Bayona Rangel y Carlos Mario Frías Rubio, en el Grupo de Investigación Familia, Género y Conflicto del Centro de Investigaciones Laureano Gómez Serrano.

** Doctor en Derecho de la Universidad Externado de Colombia, especializado en Ciencias Penales y Criminológicas en la misma Universidad, Docente de la Facultad de Derecho de la Universidad Autónoma de Bucaramanga, profesor titular de Derecho Penal General. Correo electrónico: rmantilla3@unab.edu.co.

*** Abogada egresada de la Universidad Autónoma de Bucaramanga, especializada en Derecho Penal de la misma universidad, Docente de la Facultad de Derecho de la Universidad Autónoma de Bucaramanga, profesora titular de Derecho Procesal Penal y Análisis jurisprudencial. Correo electrónico: Jbayona8@unab.edu.co.

**** Abogado egresado de la Universidad Autónoma de Bucaramanga, especializado en Derecho Penal de la misma universidad, Docente de la Facultad de Derecho de la Universidad Autónoma de Bucaramanga, profesor titular seminario de hermenéutica jurídica penal y Seminarios de investigación en derecho penal. Correo electrónico: cfrias@unab.edu.co. 


\title{
A DOGMATIC ANALYSIS OF THE CRIME OF PROCEDURAL FRAUD FROM THE POINT OF VIEW OF ITS CONTENTS AND CASE-LAW DEVELOPMENT IN THE SUPREME COURT
}

\begin{abstract}
This articles examines the dogmatic characteristics of the crime of procedural fraud and its development in the criminal chamber of the Supreme Court from the perspective of criminal law as a guarantee for all citizens. The article describes the theoretical characteristics of this crime, as well as development of rules, which are questioned by the guarantees of the principle of typicality.
\end{abstract}

Keywords: procedural fraud, typicality, prescription, continuous crime, result crime.

\section{ANÁLISE DOGMÁTICO DO TIPO PENAL DA FRAUDE PROCESSUAL DO PONTO DE VISTA DO SEU CONTEÚDO E DESENVOLVIMENTO JURISPRUDÊNCIAL NA CORTE SUPREMA DE JUSTIÇA RESUMO}

$\mathrm{O}$ artigo de pesquisa se pergunta pelas características dogmáticas do tipo penal de fraude processual e seu desenvolvimento perante a Câmara do Supremo Tribunal Penal, visto a partir da perspectiva do direito penal como uma garantia para todos os cidadãos. Se encontram as características teóricas deste tipo penal assim como um desenvolvimento de regras jurisprudenciais que são questionadas pelas garantias emitidas do princípio de tipicidade.

Palavras-chave: fraude processual, tipicidade, prescrição, delito de execução permanente, delito de resultado.

\section{INTRODUCCIÓN}

El derecho Penal que se desarrolla bajo la vigencia de la Constitución Política de 1991 responde esencialmente a la ponderación entre los intereses de la sociedad y algunas conductas humanas que afectan valores sociales de manera tan severa que deben ser reprimidas mediante la privación de la libertad.

El ejercicio de tal poder sobre los ciudadanos está regido por principios que regulan y mantienen la integridad de los Derechos Fundamentales; dentro de tales principios se encuentra la tipicidad como forma 
especializada del principio de legalidad, de este instituto jurídico básico se deriva toda una teoría para el entendimiento y aplicación de los tipos penales en un contexto de Estado de Derecho fundado en el respeto a la dignidad humana.

La teoría que rige la aplicación del principio de tipicidad y su aplicación por parte de los altos Tribunales es el objeto de la presente investigación en la que se indagará por la correcta aplicación del artículo 453 del Código Penal como garantía en la tensión que se presenta entre los derechos fundamentales ciudadanos y de los intereses superiores de la sociedad, que en este caso toman la forma del bien jurídico de la función pública.

El problema de investigación propuesto partió de la pregunta ¿Cuál es el desarrollo normativo del tipo penal de fraude procesal?

El presente artículo tiene por objeto la determinación de las características dogmáticas del tipo penal contentivo del delito de fraude procesal, de tal manera que se permita concluir sobre las implicaciones y aplicación de este tipo penal en correspondencia con la teoría del delito y que en consecuencia atienda a las garantías constitucionales que debe ofrecer el Derecho Penal moderno a partir de las estructuras dogmáticas, en tanto la hipótesis de trabajo es que el tipo penal de fraude procesal atiende las garantías constitucionales que se concretan en el principio de tipicidad.

Para cumplir con el propósito propuesto, la investigación se desarrolló en dos etapas, la primera es la descripción del desarrollo jurisprudencial del tipo de fraude procesal en la Sala Penal de la Corte Suprema de Justicia como tribunal de cierre en materia de Derecho Penal.

Posteriormente se realizará un análisis desde la dogmática penal por medio del cual se pretende dar a conocer al lector cómo el concepto actual del tipo penal de fraude procesal puede estar obstruyendo garantías constitucionales y legales y plantear una posición desde la Dogmática Penal que cuestione y formule una postura diferente que permita cumplir los fines constitucionales del Derecho Penal.

\section{DESARROLLO JURISPRUDENCIAL DEL DELITO DE FRAUDE PROCESAL}

La Corte Suprema de Justicia tiene como un asunto decantado las características dogmáticas del tipo penal de fraude procesal que ha determinado como un delito de conducta permanente en tanto la lesión al 
bien jurídico se prolonga durante todo el tiempo que la autoridad se mantenga en error (CSJ-SP, 4 feb. 2015, 41641, (AP) E. FERNÁNDEZ CARLIER); además de ser un delito de mera conducta al no exigirse la producción del resultado (CSJ-SP, 30 jul. 2014, 42014, (AP) P. SALAZAR CUÉLLAR), y que finalmente se entiende materializado cuando el estado de ilicitud creado por vía del error en el funcionario público deja de producir efectos (CSJ-SP 8 jul. 2015, 46204, (AP) G. MALO FERNÁNDEZ). Dicha posición se ha desarrollado, mantenido y reiterado de manera constante en la jurisprudencia colombiana y será abordada de manera cronológica en el desarrollo de este análisis.

A continuación se presenta un gráfico con el estudio de línea realizado a partir del problema jurídico con el fin que el lector tenga presente las variantes del criterio de la Corte en el tiempo.

\begin{tabular}{|c|c|c|}
\hline \multicolumn{3}{|c|}{$\begin{array}{l}\text { ¿Es el tipo de fraude procesal un delito de ejecución permanente que permite contar su } \\
\text { prescripción desde el último acto realizado por el autor sin incluir en esta los } \\
\text { efectos/consecuencias de su comisión/ de la comisión del acto de consumación? }\end{array}$} \\
\hline SI & \multirow{2}{*}{$\begin{array}{c}\text { S. } 8968 \\
17 / 07 / 1995\end{array}$} & $\mathrm{NO}$ \\
\hline \multirow{13}{*}{$\begin{array}{l}\text { El tipo penal de fraude } \\
\text { procesal es un delito que } \\
\text { desde su contenido se } \\
\text { clasifica como de mera } \\
\text { conducta y de ejecución } \\
\text { permanente. Lo anterior } \\
\text { indica que se consuma con } \\
\text { la inducción en error al } \\
\text { funcionario y su ejecución } \\
\text { se prolonga hasta la } \\
\text { ejecutoria del último acto } \\
\text { que puede ser } \\
\text { administrativo o judicial, } \\
\text { de acuerdo con plan } \\
\text { criminal del agente. }\end{array}$} & & \multirow{13}{*}{$\begin{array}{l}\text { El tipo penal de fraude } \\
\text { procesal es un delito que } \\
\text { desde su contenido se } \\
\text { clasifica como de mera } \\
\text { conducta y de ejecución } \\
\text { permanente. Lo anterior } \\
\text { indica que se consuma con } \\
\text { la inducción en error al } \\
\text { funcionario y su ejecución } \\
\text { se prolonga hasta que cesen } \\
\text { los efectos jurídicos del } \\
\text { acto o los actos que se } \\
\text { generaron por vía del ardid } \\
\text { en que se indujo al } \\
\text { funcionario. }\end{array}$} \\
\hline & S. 9134 & \\
\hline & & \\
\hline & $\begin{array}{l}\text { S. } 11210 \\
4 / 10 / 2000\end{array}$ & \\
\hline & S 20013 & \\
\hline & $5 / 10 / 2004$ & \\
\hline & $\begin{array}{c}\text { S. } 28562 \\
18 \text { de junio de } 2008\end{array}$ & \\
\hline & S. 27710 & \\
\hline & 18 de marzo de 2009 & \\
\hline & $\begin{array}{l}\text { A } 3 / 856 \\
7 / 10 / 2011\end{array}$ & \\
\hline & $\begin{array}{l}\text { A } 42552 \\
4 / 12 / 2013\end{array}$ & \\
\hline & $\begin{array}{c}\text { A44980 } \\
3 / 12 / 2014\end{array}$ & \\
\hline & $\begin{array}{l}\text { A46204 } \\
8 / 6 / 2015\end{array}$ & \\
\hline
\end{tabular}

El tipo penal de fraude procesal es un delito que desde su contenido se clasifica como de mera conducta y de ejecución permanente. Lo anterior indica que se consuma con la inducción en error al funcionario y su ejecución se prolonga hasta la ejecutoria del último acto que puede ser administrativo o judicial, de acuerdo con plan criminal del agente. 
El tipo penal de fraude procesal es un delito que desde su contenido se clasifica como de mera conducta y de ejecución permanente. Lo anterior indica que se consuma con la inducción en error al funcionario y su ejecución se prolonga hasta que cesen los efectos jurídicos del acto o los actos que se generaron por vía del ardid en que se indujo al funcionario. Una vez el lector ha visualizado el transcurrir de la línea conforme al criterio de la Corte se iniciará su análisis así:

En sentencia del 17 de agosto de 1995 (CSJ-SP, 17 ago. 1995, 8968, (SP) F. ARBOLEDA RIPOLL) la Corte decide el caso de fraude procesal en el cual el agente inicia proceso de restitución de bien mueble arrendado con contrato falso, en tanto el tenedor era copropietario del bien mueble; esto desencadena un proceso civil en el que el demandante pretende declarar el incumplimiento de un contrato y obtener la restitución material de un bien valiéndose del ejercicio de la función jurisdiccional, cuestión que de acuerdo con la realidad el Derecho no podría otorgar. Que para hacerse con bienes que de acuerdo a la realidad, el derecho no hubiese otorgado al demandante.

El proceso civil se inició con la presentación de la demanda fraudulenta, la cual fue admitida y surtió el trámite de rigor, dentro del cual la justicia, soportándose en el documento falso, pronunció a favor del demandante sentencias de primera y segunda instancia. Una vez obtenida la firmeza de esta decisión el demandante procedió a la ejecución de la sentencia mediante el trámite del correspondiente despacho comisorio ante la autoridad de policía.

Con ocasión al proceso civil, el demandado denunció penalmente al demandante quien fue procesado y condenado como autor de la conducta punible de fraude procesal. Luego de agotarse los recursos legales ordinarios, la defensa concurrió ante la Sala Penal de la Corte Suprema de Justicia, mediante el recurso extraordinario de casación, actuación que propició para que esta se pronunciara sobre el asunto.

La demanda de casación tuvo como fundamento la solicitud de prescripción de la acción penal mediante el argumento que refiere que el cómputo de la misma debe hacerse desde la presentación de la demanda, es decir, desde la presentación del medio idóneo para la inducción en error al servidor público. Respecto de dicha petición la Corte responde:

(...) puede tratarse de un delito cuya consumación se produzca en el momento histórico preciso en que se induce en error al 
empleado oficial, si con ese error se genera más o menos de manera inmediata la actuación contraria a la ley. Pero si el error en que se indujo al funcionario, se mantiene durante el tiempo necesario para producir la decisión final contraria a la ley cuya finalidad se persigue, y aún con posterioridad a ésta, si requiere de pasos finales para su cumplimiento, durante todo ese lapso se incurre en la realización del tipo y la violación al bien jurídico tutelado, pues durante ese tiempo se mantiene el fraude a la administración de justicia.

Por ello, "para los fines de la prescripción de la acción penal, el término sólo debe contarse a partir del último acto de inducción en error, o sea desde cuando la ilícita conducta ha dejado de producir sus consecuencias y cesa la lesión que por este medio se venía ocasionando a la administración de justicia "(C.S.J. Sala de Casación Penal. Sentencia del 27 de junio de 1989. M.P. Dr. Jorge Carreño Luengas).

Frente al caso en estudio, la Corte considera que el condenado induce en error al Juzgado mediante la presentación de la demanda soportada en un contrato falso, se mantiene el error en tanto que los entonces demandantes para responder a la tacha de falsedad propuesta por la víctima del delito presentan nuevos documentos falsos continuando el proceso hasta obtener sentencia y con el propósito de ejecutarla se tramita despacho comisorio ante autoridad de policía.

En la sentencia se observa la descripción de la Corte Suprema en relación al fraude procesal para la época, en primer lugar la Sala Penal entiende el tipo penal de fraude procesal como un delito de resultado al afirmar que se consuma en el momento en que se induce en error al servidor. En segundo lugar, en lo referente a la duración de la consumación del acto delictivo, considera que el tipo penal en estudio es de ejecución permanente visto desde la perspectiva del bien jurídico que se piensa vulnerado por el sujeto activo del delito en el lapso que se mantenga al servidor público en error.

Agrega la Corte que la consumación y duración de ejecución del tipo en estudio se estima en relación con el tiempo en el que se mantiene en error al funcionario judicial, lo cual incluye el tiempo posterior a la toma de la decisión contraria a derecho perseguida por el sujeto activo, hasta tanto se reversen los efectos que obtuvo el autor con la inducción; por consiguiente, este último incurre durante todo ese lapso en la realización 
del tipo penal y como consecuencia, en la vulneración del bien jurídico tutelado.

Respecto de la prescripción, la Corte considera que esta debe contarse a partir de la última actuación, es decir, para el caso en estudio, el trámite del despacho comisorio, el cual es definido como el momento en que la conducta ha dejado de producir efectos y se da por terminada la lesión al bien jurídico.

Así las cosas, no se concede la prescripción del delito de fraude procesal porque de acuerdo con el criterio de la Corte la duración de la ejecución del delito se estima con relación al lapso en que se mantenga el servidor en error y se provean decisiones de acuerdo con el plan criminal del autor.

Finalmente, en la sentencia en estudio, la Corte, realiza una explicación en relación con la prescripción del delito de fraude procesal, acotación que como se observará se irá desvaneciendo con las decisiones posteriores.

Por ello, "para los fines de la prescripción de la acción penal, el término sólo debe contarse a partir del último acto de inducción en error, o sea desde cuando la ilícita conducta ha dejado de producir sus consecuencias y cesa la lesión que por este medio se venía ocasionando a la administración de justicia "(C.S.J. Sala de Casación Penal. Sentencia del 27 de junio de 1989. M.P. Dr. Jorge Carreño Luengas).

Lo anterior, porque aunque el funcionario puede permanecer indefinidamente en error, al estar convencido de que la decisión que tomó era la jurídicamente viable y la más justa de acuerdo con la realidad a él presentada, para todos los efectos jurídicos sean sustanciales o procesales, debe haber un límite a ese error, y este límite no puede ser otro que la misma ejecutoria de la resolución o acto administrativo contrario a la ley, cuya expedición se buscaba, si allí termina la actuación del funcionario, o con los actos necesarios posteriores para la ejecución de aquella, pues de lo contrario, la acción penal se tornaría en imprescriptible, lo cual riñe con el mandato constitucional al respecto."

La Corte comprende que si el funcionario se mantiene en error indefinidamente debe existir un límite en el término de ejecutoria de la conducta para evitar que el delito se torne imprescriptible y en ese 
sentido la corporación llega a la conclusión de que la prescripción se debe contar a partir de la realización del último acto, que puede ser la ejecutoria de la resolución o acto administrativo contrario a derecho pretendido por el autor del delito, o los actos que, con ocasión a la providencia, deban ejecutarse.

De lo anterior puede afirmarse que la Corte desdibuja el ingrediente subjetivo del tipo penal "obtener acto administrativo o providencia contraria a derecho" y lo confunde con los elementos objetivos del tipo penal que finalmente son los que pueden determinar la naturaleza del delito para efectos del cómputo de la prescripción.

En providencia posterior, del 30 de octubre de 1996 ( CSJ-SP, 30 oct. 1996, 9134, (SP), D. PÁEZ VELANDIA) la Corte resolvió caso de proceso ejecutivo en el que la parte demandada presentó una prueba de extinción de la obligación por pago mediante la cual se indujo erróneamente al juez quien, de acuerdo $\mathrm{CON}$ dicha prueba, dio por terminado el proceso.

Finalizado el proceso civil, el demandante inició proceso penal que luego del trámite procedente culminó condenando al que en su momento fue el civilmente demandado, para efectos del proceso penal condenado, por el delito de fraude procesal. La defensa interpuso los recursos legales y en sede de casación planteó la prescripción de la acción penal.

Fundamentó su petición en la necesidad de diferenciar, para efectos del cómputo de la prescripción, el momento en que el sujeto activo realiza el acto de inducción en error el cual es disímil al lapso en que el funcionario puede permanecer en él. De acuerdo a lo anterior, el libelista consideró que la Corte debía declarar la prescripción de la acción penal en el sentido DE que para el delito de fraude procesal esta debe contarse únicamente en el momento en que el autor realiza el acto de inducción en error al funcionario descartando la tesis que pretende contabilizarla desde la acción de inducción y el lapso en el cual permanece el funcionario en dicho yerro.

La Corte discrepó del planteamiento del recurrente y en cambio sostuvo que el tipo penal de fraude procesal es de conducta permanente porque la lesión al bien jurídico que se genera con el acto fraudulento desplegado por el sujeto activo se mantiene mientras subsista la maniobra engañosa y produzca efectos sobre el funcionario que se encuentra en error hasta la producción del resultado esperado por el autor y aún podría llegar 
prolongarse a instancias posteriores. Así mismo, consideró que la lesión al bien jurídico cesa con la ejecutoria de la providencia fraudulentamente obtenida.

La Corte manifestó dichas conclusiones así:

(...) el comportamiento del agente activo del delito en el fraude procesal es de los que producen la lesión al bien jurídico amparado por el Estado a partir de un momento dado, prolongándose esa lesión en el tiempo hasta cuando se pone fin a la conducta. Es pues, un tipo penal de conducta permanente.

Se inicia con el acto de incoar la pretensión mediante la inducción en error al funcionario oficial, bien sea que esa pretensión se mantenga con el único e inicial acto, o con la impulsión del procedimiento mediante actos posteriores igualmente de inducción dependientes de las eventualidades sobrevinientes orientados a la consumación del hecho punible y que por consiguiente asumen la condición de hitos reiterativos del iter criminoso, con trascendencia propia para efectos de la prescripción. La consumación del delito continúa pues, mientras dura el estado de ilicitud, que no es otro que el de la inducción ejercida en el funcionario.

Ello se explica porque el fin perseguido por el agente es el logro de un determinado pronunciamiento del funcionario oficial y, siendo lo común que para arribar a ese objetivo antecedan una serie de actos tanto de las partes trabadas en la litis -cuando de estas se trata- como del juez en desarrollo del procedimiento, resulta evidente la permanencia cronológica de la conducta ilícita en tanto el funcionario se halle en el error.

...Por eso ha dicho esta Sala, reiterando su conocido criterio jurisprudencial en torno al asunto, que "la vulneración al interés jurídico protegido por la norma se prolonga a través del proceso durante el tiempo en que la maniobra engañosa siga produciendo sus efectos sobre el empleado oficial".

Siendo claro que la lesión del interés jurídico protegido cesa con la ejecutoria de la providencia fraudulentamente obtenida, se explica que también la Sala haya precisado en 
concomitancia con lo anterior: "De ahí que para los fines de la prescripción de la acción penal, el término sólo debe contarse a partir del último acto de inducción en error; o sea desde cuando la ilícita conducta ha dejado de producir sus consecuencias y cese la lesión que por este medio se venía ocasionando a la administración de justicia.". (Auto 26 sept. 1995, Rad.8903 M.P.Dr. Páez Velandia).”(Ídem)

De acuerdo con las anteriores premisas, la Corte consideró que la prescripción de la acción penal para el tipo penal de fraude procesal debe contabilizarse desde que la conducta engañosa deja de producir efectos, ya sea un solo acto fraudulento o actos posteriores como la ejecutoria del acto o providencia y en ese sentido, para la Corte es en ese momento que cesa la lesión ocasionada a la administración de justicia.

En el año 2000, con sentencia del 4 de octubre del año 2000 (CSJ-SP, 4 oct. 2000, 11210, (SP), C. MEJIA ESCOBAR) la Corte decidió sobre un caso en el que fraudulentamente se presentó demanda civil de declaración de pertenencia soportada en testigos falsos con el propósito de que el derecho de propiedad sobre bien inmueble fuera declarado a favor del demandante.

Conocido lo anterior por la justicia penal se condenó al sujeto agente por el delito de fraude procesal quien luego de agotar los recursos legales presentó demanda de casación en la que solicitó decretar la prescripción de la acción penal ya que dicho término debía ser contabilizado a partir de la fecha presentación de la demanda civil, con la cual se inició y perfeccionó la conducta punible, y que posteriormente fue objeto de la investigación penal.

La Corte negó la solicitud argumentando:

Como lo ha reiterado la jurisprudencia de esta Sala, se trata de un delito de carácter permanente pues la lesión al bien jurídico protegido por la norma perdura por todo el tiempo en que el funcionario judicial permanezca en error. Es decir, que dicha vulneración se prolonga durante todo el lapso en que los mecanismos fraudulentos incidan en el funcionario oficial. Es entonces, a partir del último acto de inducción en error que empieza a correr el término prescriptivo.

Por ello no resulta aceptable la tesis del demandante consistente en que en el asunto objeto de revisión, el "Iter Criminis" 
comenzó con la presentación de la demanda ante el Juzgado 22 Civil del Circuito de Bogotá, para derivar de allí que con ese solo acto se agotó la conducta y a partir de allí, septiembre de 1985, empezó a transcurrir el término de prescripción.

En ese sentido la Corte conceptuó sobre el tipo penal de fraude procesal así:

El fraude procesal, por ser un delito de simple conducta, se consuma con la inducción en error, previa ejecución de los actos engañosos que desdibujan la realidad, sin que sea necesaria la materialización de un perjuicio o de un beneficio, más allá de lo que el acto funcional mismo tenga de perjudicial o beneficioso. No es por tanto una exigencia del tipo, el que se obtenga un resultado, v. gr., en términos de un efectivo desplazamiento patrimonial, porque se considera agotado cuando se realiza el comportamiento descrito en el verbo rector "inducir", que es el que constituye el núcleo de la acción. (Ídem)

Como se advierte en líneas precedentes, la Corte, al negar la petición del recurrente clasificó el tipo penal de fraude procesal como un delito de mera conducta que se consuma con la inducción en error del servidor, que además su ejecución es de carácter permanente en tanto que la lesión al bien jurídico se mantiene por el tiempo en que el funcionario permanezca en el yerro creado a voluntad del autor.

En consecuencia, de acuerdo con la sentencia en mención la Corte consideró que el término de prescripción para el tipo penal de fraude procesal debía contarse a partir del último acto de inducción, y asumió como tal la última providencia o acto administrativo que profirió el funcionario bajo el yerro creado. Para el caso en estudio, el último acto de inducción fue la decisión de segunda instancia ya que hasta ese momento se prolongó la inducción en error. En tal sentido, de haber conocido la verdad real, los funcionarios habrían tomado una decisión distante a la discutida.

En el mismo fallo aclara la Corte que para que el delito de fraude procesal se entienda plenamente agotado no se requieren actos posteriores, como lo sería el registro de la sentencia en notariado y registro, porque reitera que el tipo penal en estudio no requiere un resultado, y su permanencia se deriva de la lesión al bien jurídico. 
Ahora bien, en providencia de 2004 (CSJ-SP, 5 may. 2004, 20013, (SP), M. PULIDO) La Corte se pronunció de nuevo sobre el delito de fraude procesal y mantuvo el criterio precedente teniendo en cuenta la regla que previó en sentencia del 17 de Agosto de 1995 respecto de la prescripción de la acción penal.

En el caso referido, 2004, un sujeto falsificó títulos valores a cargo de persona desaparecida con el fin de promover procesos ejecutivos que lo beneficiarían. Una vez conocida la conducta punible por la justicia penal se realizó el proceso respectivo el cual culminó con sentencia condenatoria. El abogado de la defensa propuso el recurso extraordinario de casación en donde alegó que la prescripción de la acción penal en el delito en mención debía contarse desde el último acto procesal realizado por el sujeto activo, que para el caso sub iúdice se refiere a la objeción de la liquidación del crédito que es fallada a favor del para entonces demandante, luego condenado penalmente, y a la solicitud de reducción de embargo, ambos actos desplegados en procesos ejecutivos.

La cita en que la Corte aborda la regla jurisprudencial mediante la que resuelve el caso es la siguiente:

(...) se tiene que acerca del referido comportamiento punible esta Sala ha tenido oportunidad de precisar que se trata de un delito que si bien para su consumación no requiere resultado alguno, es de carácter permanente, en cuanto comienza con la inducción en error al funcionario judicial o administrativo, pero se prolonga en el tiempo, en tanto subsista la potencialidad de que el error siga produciendo efectos en el bien jurídico, razón por la cual el término de prescripción comienza a contarse a partir del último acto. (Ídem)

Así las cosas se advierte incólume el argumento de la Corte mediante el cual afirma que el tipo penal de fraude procesal primero, no requiere resultado alguno, es un delito de mera conducta; segundo, que su ejecución comienza con el acto o actos de inducción en error al funcionario y se prolonga en el tiempo en tanto subsista la potencialidad de que el error siga produciendo efectos, es decir es una conducta de tipo permanente. No obstante, la Corte, al advertir que, de acuerdo con la clasificación realizada podría tornar el tipo en imprescriptible, consideró que debe existir un límite al término de prescripción y en ese sentido se pronuncia citando la sentencia del 17 de agosto de 1995: 
(...) Lo anterior, porque aunque el funcionario puede permanecer indefinidamente en error, al estar convencido de que la decisión que tomó era la jurídicamente viable y la más justa de acuerdo con la realidad a él presentada, para todos los efectos jurídicos sean sustanciales o procesales, debe haber un límite a ese error, y este límite no puede ser otro que la misma ejecutoria de la resolución o acto administrativo contrario a la ley, cuya expedición se buscaba, si allí termina la actuación del funcionario, o con los actos necesarios posteriores para la ejecución de aquella, pues de lo contrario, la acción penal se tornaría en imprescriptible, lo cual riñe con el mandato constitucional al respecto.

Teniendo en cuenta que el tipo penal de fraude procesal es de conducta permanente, de acuerdo con el criterio de la Corte, con el fin que el mismo no se torne imprescriptible ha de contarse el término de prescripción desde la ejecutoria del acto contrario a derecho proferido o desde los actos posteriores necesarios para su ejecución, en el caso de que haya lugar a estos.

De acuerdo con lo anterior, la Corte computó la prescripción a partir del momento en que se produjo la última providencia producto del delito, contrario a la primera y segunda instancia quienes consideraron que el delito se prolongaba en el tiempo mientras surtiera efectos jurídicos el acto o providencia contraria a derecho, lo cual para el caso en estudio dio como resultado la declaración de la prescripción de la acción penal en la siguientes palabras:

Así las cosas, encuentra la Sala que la causal de revisión invocada está llamada a prosperar, motivo por el cual corresponde dejar sin valor el trámite surtido con posterioridad a las fechas en las cuales operó el fenómeno extintivo de la acción de los delitos de fraude procesal imputados al procesado FANDIÑO $\mathrm{COBO}$, resultando imperativo, en consecuencia, declarar la prescripción de los referidos comportamientos, causada con anterioridad a la fecha en que cobró ejecutoria la resolución acusatoria, y por tanto, ordenar la cesación del procedimiento que se adelantó por tales punibles."(CSJ-SP, 5 may. 2004, 20013, (SP), M. PULIDO)

En sentencia de 18 de junio del año 2008 (CSJ-SP, 18 jun. 2008, 28562, (SP), A. IBÁÑEZ GUZMÁN), la Corte Suprema decidió el caso de 
fraude procesal en el que un sujeto usando documentos apócrifos obtiene una pensión del sistema de seguridad social quien con base en los medios fraudulentos presentados por el autor e inducido en error la decretó a través de acto administrativo.

Luego del estudio correspondiente, la Sala negó la pretensión de prescripción incoada mediante demanda de casación bajo el sustento de que al ser, el fraude procesal, un tipo penal de ejecución permanente, y al no exigirse un resultado, su consumación consta de dos partes; la primera, cuando se induce en error al servidor y la segunda, que indica que la ejecución del delito perdura mientras se mantenga dicho estado de ilicitud en el tiempo. Argumento que tuvo influencia directa con respecto al cómputo de la prescripción de la acción penal; lo anteriormente expresado se extracta así:

(...) Si bien no se exige que se produzca el resultado perseguido, se entiende consumado cuando el agente, de manera fraudulenta, induce en error al servidor. Pero perdura mientras se mantiene el estado de ilicitud y aun con posterioridad si se requiere de pasos finales para su cumplimiento.

Así, la Corte haciendo un recuento de la jurisprudencia concluyó que no es cierto que la prescripción del tipo penal de fraude procesal se cuente desde la ejecutoria de la providencia objeto de fraude, y en cambio afirmó que:

(...) El recuento demuestra que no es cierto que la jurisprudencia haya entendido uniformemente que el término de prescripción respecto del delito de fraude procesal empezaba a contarse desde cuando adquiría firmeza la decisión que reconocía las pretensiones ilegales.

Es evidente que lo sostenido era y sigue siendo, salvo lo que más adelante se explica, que ese lapso se contabiliza a partir del último acto de inducción en error, entendiendo éste no como aquel momento histórico en el que el servidor público dictó el acto contrario a la ley -cuando ello alcanza a materializarse- sino hasta cuando la ilícita conducta ha dejado de producir sus consecuencias y cese, en consecuencia, la lesión que por ese medio se venía ocasionando a la administración. (Ídem) 
En el caso relatado, la Corte consideró que el delito se mantuvo en el tiempo, no solo hasta la expedición del acto administrativo, sino que también durante el lapso que este tuvo vigencia y solo finalizó su consumación hasta que la administración superó el error mediante la revocatoria del acto administrativo. Dicha decisión es analizada en los siguientes términos:

José Ignacio Castañeda Neira presentó solicitud con el fin de que le fuera reconocida $y$, por ende, pagada una prestación periódica: su pensión de jubilación, para lo cual aportó certificaciones con las que acreditaba el tiempo de servicio necesario para ese fin. Unas de ellas, las relativas a su desempeño en el cargo de Secretario del Concejo Municipal de Jenezano, resultaron ser apócrifas.

...La maniobra engañosa ejercida sobre esa autoridad inició su consumación con la presentación del documento apócrifo, con la cual se indujo en error al servidor, que tuvo como legal, válida y ajustada a la realidad la información allí contenida, y, contrario a lo afirmado por el recurrente, ese ardid no finalizó con la expedición del acto administrativo del 19 de diciembre de 1988, porque:

El acto cuya expedición se pretendía no era de simple reconocimiento de pensión, sino de reconocimiento y pago de la misma en forma periódica (mensualmente), mesada que fue cobrada por el procesado, incluso hasta la fecha en que se profirieron los fallos de instancia. Ese pago mensual, aunque tiene en cuenta cuotas partes de otras entidades, está a cargo de la misma autoridad, quien es la que luego repite en contra de aquellas.

b) De manera pues que el Fondo de Previsión Social, esto es, la misma autoridad ante la que se inició el ardid, continúa engañada, tanto que mes a mes sigue pagando la mesada pensional, confiada en que su beneficiario cumple con los presupuestos legales para ser merecedor de ella. Es claro que de haberse percatado del engaño al que fue inducida habría podido suspender los pagos y revocar, con las formalidades que exige la ley, su acto administrativo.

c) La administración tiene la facultad legal de revocar su propio acto en cualquier tiempo, acudiendo a la figura de la 
revocatoria directa contenida en el Código Contencioso Administrativo (artículos 69 y 73), es decir, por ser evidente que el acto ocurrió por medios ilegales. Esa posibilidad de revocatoria, concretamente tratándose de pensiones reconocidas irregularmente, la asintió el legislador de 2003 en la Ley 797 (artículo 19), y le impuso, además, un deber de verificación oficiosa sobre el cumplimento de los requisitos necesarios para la adquisición del derecho correspondiente.

Por consiguiente, la inducción en error se mantuvo en tanto la administración ni siquiera hizo uso del mecanismo de la revocatoria directa. "(Ídem)

Así las cosas, se advierte que existe por parte de la Corte una desafortunada técnica jurisprudencial en lo referente al amparo del precedente horizontal ya que como se observa se aparta de lo mencionado en decisión anterior, en la cual sostuvo que la prescripción para el tipo penal de fraude procesal se contabilizaba desde la ejecutoria del acto administrativo o resolución judicial producto del yerro en que se induce al servidor, para acoger otra postura en la cual consideró que el delito, al ser de carácter permanente, se entiende consumado solo en el momento en que culminen los efectos del mismo en el mundo jurídico y sólo hasta ese momento se podrá iniciar el cómputo de la prescripción.

La nueva posición de la Corte se reitera en sentencia del 18 de marzo de 2009 (CSJ-SP, 18 mar. 2009, 27710, (SP), M. GONZÁLES LEMOS) mediante un proceso penal que llegó a conocer en sede de casación sobre un caso de fraude procesal que se originó en un proceso de liquidación de sociedad conyugal en el que uno de los cónyuges presentó documentos falsos, que en su momento registró en la oficina de tránsito, respecto del dominio de un automotor, para hacer creer que este mueble se encontraba en cabeza de una tercera persona y así lograr su cometido el cual era que el juez de familia excluyera el vehículo del proceso.

Luego de culminado el proceso de familia y el penal con sentencia condenatoria, la defensa acudió al recurso extraordinario de casación en el que solicitó se declarara la prescripción con el fundamento de tenerse como término para el cómputo de la misma la inscripción en la oficina de registro automotor, La Corte negó la solicitud incoada por la defensa y se refirió al tipo penal de fraude procesal en los siguiente términos:

(...) el tipo en cita, de acuerdo con su contenido, es de aquellos denominados de mera conducta, pues basta 
ejecutar el comportamiento, ya que debido a la potencialidad dañosa del acto del sujeto agente, el legislador ha determinado que debe ser objeto de sanción penal al margen del resultado obtenido.

A su vez, es un modelo legal de conducta permanente, en tanto su consumación subsiste mientras no concluya la afectación al bien jurídico en virtud del medio fraudulento empleado.

Esta última situación conduce a precisar, también con apoyo en criterio reiterado de la Sala, que la potencialidad del daño derivado de la maniobra engañosa no se extiende hasta el querer finalístico del infractor, si se proyecta a la etapa de la causa, sino que va "hasta el cierre de investigación, y a partir de la ejecutoria de la resolución de acusación se inicia el término de prescripción de la acción penal.

En ese sentido se advierte que la Corte reiteró su criterio respecto de las características del tipo penal de fraude procesal ya que mencionó que el tipo en estudio es de mera conducta, en tanto basta ejecutar el comportamiento al margen del resultado para imponer la sanción penal, igualmente se sostiene en que al ser de conducta permanente la consumación persiste mientras no concluya la afectación al bien jurídico. Por otra parte la decisión en relación con la prescripción del delito se plantea en las siguientes palabras:

Entonces, de acuerdo con lo señalado en precedencia, es claro que la inscripción en el Registro Terrestre Automotor, como se denominaba para la época de los hechos o, ahora, en el Registro Nacional Automotor de un acto que afecte la situación jurídica de un vehículo, tendrá consecuencias mientras no se proceda a su modificación o cancelación.

Por consiguiente, como en el caso particular se tiene que hasta al momento de calificar el mérito del sumario, es decir, el 20 de noviembre de 2003, se decidió “ordenar la cancelación del registro fraudulento del automotor hecho en la oficina de tránsito", lo cual se vino a concretar el 15 de diciembre de 2005 a través de la Resolución No 454 de la Secretaría de Tránsito de Cali, de allí se sigue que los efectos de la maniobra engañosa del traspaso a Jairo Ramírez Rodríguez perduraron hasta aquella época. 
Por consiguiente, dejando a salvo la interpretación que viene haciendo la Sala según la cual en los delitos permanentes el límite temporal de los hechos sólo puede extenderse hasta el cierre de la investigación, en caso de perdurar más allá, es evidente que aun tomando en el sub júdice el supuesto fáctico referido por el censor, es decir, el episodio de la inscripción del traspaso fraudulento del vehículo automotor en la Secretaría de Tránsito de Cali, se arriba a la conclusión de que no habría prescrito la acción penal, pues el registro no sólo se mantuvo sino que produjo efectos frente a terceros, demostrando, falsamente, que Jairo Ramírez Rodríguez era el propietario del rodante. (Ídem)

Con las razones anteriores, se concluye que la Corte mantuvo el criterio mediante el cual el término de prescripción se contabiliza desde el momento en que cesan los efectos del error en que se hizo incurrir al funcionario, y en esto incluyó la presentación del documento falso y las providencias derivadas del mismo, pero además afirmó que para el caso sub júdice dicho término solo se podría contabilizar a partir de la corrección del documento que fue registrado apócrifamente teniendo en cuenta que este continuó surtiendo efectos jurídicos frente a terceros.

En 2011 el 7 de diciembre (CSJ-SP, 7 dic. 2011, 37856, (AP), A. IBÁÑEZ GUZMÁN) la posición se reitera. En este caso se trata de un docente del sector público que con el fin de aumentar su grado en el escalafón de carrera administrativa presentó diplomas y certificados falsos que fueron descubiertos en el momento de la verificación por parte de las autoridades competentes.

Luego de agotada la vía penal y condenada la defensa, ésta acudió en sede casación y solicitó se declarara la prescripción de la acción penal porque esta debía contarse a partir del último acto por tratarse de un delito de ejecución permanente; ante la solicitud la Corte diverge y afirma:

(i) Que, como así lo ha fijado la jurisprudencia de la Sala y se reitera por vía de esta misma decisión, el delito de fraude procesal no es de mera conducta sino de ejecución permanente".

ii) Que, bajo tal consideración y con base en los antecedentes procesales ya expuestos el término 
prescriptivo empezaría a correr a partir de la fecha de comisión del último acto, esto es, mayo de 2004, que corresponde a la que la administración detecta las irregularidades que los documentos contenían y cesan sus efectos. (Ídem)

En otras palabras, para la Corte el tipo penal de fraude procesal es estudiado desde su contenido como un delito de ejecución permanente que al flagelar con su ejecución de manera constante el bien jurídico de la administración de justicia sólo podría tenerse como agotado en el momento en que los efectos generados por la decisión judicial o acto administrativo producto del error cesen y sean corregidos por la administración y sólo desde ese último acto se iniciaría el computo de la prescripción de la acción penal.

En 2013 la posición de la Corte se ve reiterada (CSJ-SP, 4 dic. 2013, 42552, (AP), E. PATIÑO CABRERA) en caso de fraude procesal que se realizó mediante el empleo de escrituras públicas falsas que fueron presentadas por el sujeto agente ante la oficina de instrumentos públicos con el fin de modificar la situación jurídica de un inmueble.

Por los hechos anteriormente relatados el autor fue condenado en instancia penal por el delito de fraude procesal y en sede de casación solicitó la prescripción de la acción penal en tanto que esta debía contarse desde el último acto realizado por el sujeto activo, es decir, la presentación de las escrituras en la oficina de instrumentos públicos.

La Sala Penal de la Corte Suprema de Justicia negó la petición del libelista y reiteró que el fraude procesal es una conducta de carácter permanente que implica que la lesión al bien jurídico se prolongue durante el tiempo en que la conducta produzca efectos en el mundo jurídico.

Habida cuenta que el fraude procesal es una conducta de ejecución permanente -aspecto sobre el cual el censor no ha hecho reparo alguno-, es preciso recordar, previo a analizar lo correspondiente a la prescripción, cuál era la norma vigente para el instante del último acto, toda vez que, como con acierto lo explicó el ad quem, la jurisprudencia de esta Sala ha precisado que es la ley que rige ese momento, durante la ejecución del delito permanente, la que debe ser tenida en cuenta por el juez para fijar la sanción a imponer y, por contera, determinar el término de prescripción. 
...Si bien no se exige la producción del resultado perseguido, se entiende consumada cuando el agente, de manera fraudulenta, induce en error al servidor. No obstante, perdura mientras dura el estado de ilicitud y aun con posterioridad si se requieren pasos finales para su cumplimiento.

El carácter permanente del delito implica, entonces, que la lesión al bien jurídico tutelado se prolonga durante todo el tiempo en el que la autoridad se mantenga en el error y aun después si se requiere de actos de ejecución.

Ahora, en lo que toca con la prescripción, la jurisprudencia ha aclarado que ese término empieza a contarse, no a partir de la firmeza del acto administrativo, este caso, sino "del último acto de inducción en error, entendiendo éste no como aquel momento histórico en el que el servidor público dictó el acto contrario a la ley -cuando ello alcanza a materializarse- sino hasta cuando la ilícita conducta ha dejado de producir sus consecuencias y cese, en consecuencia, la lesión que por ese medio se venía ocasionando a la administración".

Igualmente, por su connotación permanente, es posible que, incluso, iniciado el proceso penal, la misma continúe produciendo efectos porque el funcionario se perpetúa o mantiene en el error. En este evento, la imputación fáctica se cuenta hasta que quede en firme el cierre del ciclo instructivo. Se hace un corte de cuentas ficticio.

En ese sentido, para efectos de contabilizar el término de prescripción, la Corporación ha manifestado que "debe tenerse en cuenta la fecha hasta la cual los efectos del acto fraudulento se extendieron o la del cierre de investigación si fueron más allá de él, como límite de la comisión del punible (Ídem).

Ahora bien, en providencia del 3 de diciembre de 2014 (CSJ-SP, 3 dic. 2014, 44980, (AP), M. GONZÁLES MUÑOZ) La Corte mantiene su criterio en relación con la resolución de un caso en el que mediante títulos adulterados se pretendía la ejecución de obligaciones civiles en proceso ejecutivo; tal conducta fue valorada por la justicia penal como fraude procesal por lo cual luego del procedimiento indicado para la época se impuso una sanción penal que se mantuvo en segunda instancia. 
El recurrente acudió en casación con la pretensión de que se declarara la prescripción de la acción penal en razón de que esta debía computarse desde el último acto, que para la defensa era la presentación de los títulos adulterados, sin embargo, luego del análisis del caso en mención, la Corte reitera que el tipo penal de fraude procesal es de mera conducta y de ejecución permanente y en ese sentido como el juzgado civil continuó con el proceso de libramiento de mandamiento ejecutivo, no era posible predicar que allí se consumaba el delito en estudio en tanto los medios fraudulentos que indujeron al juez en error, así sea parcialmente, continuaron surtiendo efectos jurídicos. La Corte lo manifestó de la siguiente manera:

(...) como lo tiene definido la Sala de tiempo atrás, el fraude procesal, aun cuando es un delito de mera conducta, se trata de aquellos de ejecución permanente, de manera que su consumación se prolonga en el tiempo hasta tanto siga surtiendo potencialmente sus efectos el error en que haya sido inducido el servidor público en orden a obtener sentencia, resolución o acto administrativo contrario a la ley.

En el caso materia de análisis, la actuación reporta que el 9 de julio de 2004 la jurisdicción ordinaria en lo civil ordenó continuar, aunque parcialmente, con la ejecución librada en contra de Ludys del Socorro Domínguez Rincón con ocasión de la demanda ejecutiva instaurada por la aquí procesada, luego necesario se hace concluir que hasta ese momento el medio fraudulento tuvo potencialidad de inducir en error al servidor público. (Ídem).

Finalmente en providencia del 4 de febrero de 2015 (CSJ-SP, 8 jul. 2015, 46204, (AP), G. MALO FERNÁNDEZ) se reiteró el criterio de la Corte cuando decidió sobre un caso de fraude procesal en donde se comprobó el uso de un poder falseado con el cual se realizaron, fraudulentamente, escrituras públicas de venta de bienes inmuebles, que a su vez fueron registradas en la oficina de instrumentos públicos.

La Corte Suprema calificó la conducta como fraude procesal y de cara la prescripción reiteró que al ser el fraude procesal un delito de conducta permanente se entiende materializada la conducta cuando esta deja de producir efectos. En tanto la lesión al bien jurídico en concreto se prolonga durante todo el tiempo que la autoridad se mantenga en error, así para efectos de contabilizar la prescripción debe tenerse en cuenta la 
fecha hasta la cual los efectos del acto fraudulento se extendieron en el mundo jurídico lo que incluye restablecer la situación del inmueble; la Corte lo explica así:

Sucede, empero, que los hechos no corresponden a la visión ofrecida por el demandante, quien desconoce la condición de delito permanente bajo la cual se rotula el fraude procesal, por cuyo efecto, no es en el instante en que se registraron las escrituras espurias en la correspondiente oficina, que deben entenderse materializados los dos punible atribuidos a ambos acusados, sino cuando estas conductas dejaron de producir efectos, asunto que se remite, cuando más, a fecha reciente, pues, el expediente informa que pese a varias solicitudes de la Fiscalía, no fue posible que los registros en cuestión fueran cancelados.

De esta manera termina el desarrollo jurisprudencial del tipo penal de fraude procesal que se ha presentado en la Sala Penal de la Corte Suprema de Justicia que ha concluido que se trata de un delito de mera conducta y de ejecución permanente. En consecuencia a esta última característica del tipo penal, las reglas jurisprudenciales para el cómputo de la prescripción hacen que se tengan en cuenta los efectos de la conducta y la cesación de aquellos para entender que la acción típica ha finalizado y pueda iniciarse a contar el término de prescripción de la acción penal.

La anterior posición es contraria al análisis dogmático del tipo contemplado en el artículo 453 del Código Penal que a la luz de la teoría del delito carece de las características determinadas en la jurisprudencia y ostenta otras que al final se van a concretar en la garantía constitucional del tipo penal la cual es vulnerada por la interpretación de la Corte que le da a la norma penal alcances que no existen.

\section{ANÁLISIS DOGMÁTICO DEL TIPO PENAL DE FRAUDE PROCESAL}

La Sala Penal de la Corte Suprema de Justicia ha sostenido en forma reiterada y pacífica en sus constantes manifestaciones jurisprudenciales que el tipo penal que establece el delito de fraude procesal es desde el punto de vista de su contenido un tipo penal de mera conducta y de conducta permanente. 
Así las cosas, la Sala se ha permitido elaborar una juiciosa doctrina sobre asuntos puntuales dentro de la teoría del delito, tales como afirmar que se trata de una conducta punible que no admite el fenómeno de la tentativa y que el término de prescripción de la acción penal sólo empieza a contarse a partir del momento en que se realice el último acto de la conducta permanente.

Consideramos que esta postura reiterada y pacífica de la Sala Penal de Corte Suprema de Justicia debe ser estudiada desde la doctrina penal lo cual permitirá proponer la revisión de la clasificación que ha venido haciendo la Jurisprudencia de la Corte Suprema en relación con el delito de fraude procesal.

\section{Problema Jurídico.}

El problema jurídico que planteamos en este caso trata de resolver si el tipo penal que establece el delito de fraude procesal es desde el punto de vista de su contenido

a. un tipo penal de mera conducta o de resultado y

b. un tipo penal de conducta instantánea, permanente o de estado.

Para resolver este asunto debemos abordar en primer lugar lo relativo a la clasificación del tipo penal contentivo del delito de fraude procesal como un tipo penal de mera conducta o de resultado y en segundo término haremos el estudio pertinente para precisar si frente a este mismo tipo penal estamos en presencia de un tipo penal de ejecución instantánea, permanente o de estado.

a. ¿El Tipo Penal de Fraude Procesal es un Tipo Penal de Mera Conducta o de Resultado?

Tipos penales de mera conducta y de resultado

La doctrina penal al realizar el estudio analítico de los tipos penales propone clasificarlos atendiendo a su contenido. En palabras de Reyes Echandía: "Esta clasificación se refiere a los diversos aspectos a que da lugar la técnica empleada por el legislador para describir los modelos de comportamiento susceptibles de sanción penal" (REYES ECHANDÍA 1981, página 170)

Bajo ese concepto en una primera clasificación distingue entre los tipos penales de mera conducta y los tipos penales de resultado. 


\section{-Tipos penales de mera conducta.}

Señalándose que los tipos penales de mera conducta se caracterizan porque en la redacción de su modelo conductual el legislador describe como punible el simple comportamiento del sujeto activo, dada la potencialidad criminosa de la acción desplegada, sin exigir la producción de un determinado resultado. (REYES ECHANDÍA 1981, página 171)

Roxin afirma que "son delitos de mera actividad aquellos en los que la realización del tipo coincide con el último acto de la acción y por tanto no se produce un resultado separable de ella."(ROXIN, 1997, Página 328) pone como ejemplo de ellos entre otros el allanamiento de morada en el que el tipo se cumple con la intromisión, el falso testimonio que no requiere un resultado que vaya más allá del juramento en falso, o también en las acciones sexuales que llevan en sí mismas su desvalor y cuya punibilidad no presupone ningún resultado ulterior. (ROXIN, 1997, Página 328).

Jescheck los define como tipos de mera actividad en los que "el tipo de injusto se agota en la acción del autor sin que el resultado (en el sentido de un efecto externo diferenciable espacio-temporalmente) deba sobrevenir" (JESCHECK, 2002, página 282) llamando como ejemplo la mayoría de los delitos sexuales y el falso testimonio. Entiende el autor que para este género de tipos penales el resultado típico debe distinguirse del menoscabo del bien jurídico protegido.

En tanto el resultado típico es la lesión o puesta en peligro del objeto material separable de la acción en una dimensión espacial y temporal mientras que la lesión o menoscabo al bien jurídico afecta la relación de la conducta típica con la pretensión de proteger el bien jurídico del tipo penal.

De los tipos penales de mera conducta se propone una subdivisión en tipos penales de mera conducta puros y tipos penales de mera conducta que hacen referencia a un resultado pero sin exigir su cumplimiento.

Explica Reyes Echandía que en los tipos penales puros de mera conducta, el legislador sólo describe la conducta sin referencia a algún resultado buscado por el sujeto agente.

Mientras que los tipos penales de mera conducta en los que se hace referencia a un resultado, este resultado no es exigido para la plena adecuación típica, pero el tipo si exige en el agente el propósito de 
producir un resultado, lo cual ocurre en los tipos penales de mera conducta con ingrediente subjetivo.

Para hacer más explícitos los conceptos anteriores es un tipo penal de mera conducta puro por ejemplo el tipo que describe el delito de falso testimonio, modalidad delictiva en la que incurre quien en actuación judicial o administrativa, bajo la gravedad del juramento ante autoridad competente, falte a la verdad o la calle total o parcialmente (Artículo 442, Código Penal Colombiano).

En esta descripción típica es claro que al legislador le basta para estimar cumplida la hipótesis delictiva, que el deponente- falte a la verdad o la calle total o parcialmente- lo cual ocurre en el acto mismo de la deposición, sin que tenga que comprobarse resultado consecuencial alguno, o comprobarse siquiera un propósito motivador de la conducta que acompañe al sujeto agente en la realización de su comportamiento.

En cambio es un tipo penal de mera conducta que hace referencia a un resultado, por ejemplo el tipo que describe el delito de rebelión, modalidad delictiva en la que incurren quienes -mediante el empleo de las armas pretendan derrocar al Gobierno Nacional o suprimir o modificar el régimen constitucional vigente- (Artículo 467, Código Penal Colombiano).

En esta descripción típica se percibe claramente que el legislador si bien no exige un resultado, bastándole para la plena consumación de la conducta delictiva el empleo de las armas, si exige la comprobación, para efectos de la realización del tipo subjetivo, la existencia del ingrediente subjetivo requerido para este delito que se concreta en la pretensión de derrocar al Gobierno Nacional o suprimir o modificar el régimen constitucional.

\section{-El proceso de adecuación típica en los tipos penales de mera conducta.}

El proceso de adecuación típica de la conducta del sujeto agente en los tipos penales de mera conducta es más sencilla en la medida en que en ese proceso no se requiere la comprobación de un nexo causal entre la conducta y el resultado. Tampoco es posible predicar la tentativa como frustración del sujeto en la consecución del resultado propuesto.

Como lo explica Roxin "en los delitos de mera actividad, para comprobar la consumación del hecho, sólo es preciso examinar la concurrencia de la propia acción del autor" (ROXIN, 1997, pp.328-329). 


\section{-Tipos penales de resultado.}

Por el contrario los tipos penales de resultado exigen que la conducta típica realizada por el sujeto produzcan el resultado previsto en el mismo tipo penal, si el evento no se produce no existe tipicidad plena. (REYES ECHANDÍA, 1981,p. 172).

Por delitos de resultado se entiende aquellos tipos en los que el resultado consiste en una consecuencia de lesión o de puesta en peligro separada espacial y temporalmente de la acción del autor" (ROXIN, 1997, p. 328).

Los delitos de resultado "presuponen la existencia en su tipo de una acción diferenciable en el espacio y en el tiempo del objeto material." (JESCHECK, 2002, p. 278).

El tipo penal de homicidio (artículo 103 del Código Penal Colombiano) es un claro ejemplo de lo que constituye un tipo penal de esta naturaleza, porque en su descripción típica el legislador exige la producción del resultado muerte para que se logre la plenitud típica de la conducta.

\section{-El proceso de adecuación típica de los tipos penales de resultado.}

El proceso de adecuación típica de los tipos penales es mucho más complejo habida cuenta del requisito de producción causal del resultado lo cual exige además de la comprobación de la conducta del agente, la constatación del nexo de causalidad lo cual en ocasiones tiene un mayor grado de dificultad que suele resolverse con la teoría de la imputación objetiva; además y teniendo en cuenta que en ocasiones no se logra el resultado típico la cuestión debe resolverse mediante el dispositivo amplificador de la tentativa.

\section{-El tipo penal contentivo del delito de fraude procesal.}

El artículo 453 del código penal establece esta conducta punible sancionando a "El que por cualquier medio fraudulento induzca en error a un servidor público para obtener sentencia, resolución o acto administrativo contrario a la ley...."

Conforme a la descripción legal el fraude procesal es un tipo penal de medios determinados porque en la descripción típica el legislador señaló expresamente la modalidad comisiva al exigir que la conducta se concrete en la colocación en error al servidor público y es también un 
tipo penal cerrado puesto que exige que el procedimiento para inducir en error sea mediante el empleo de medios fraudulentos.

El legislador también exige constatar un ingrediente subjetivo referido al propósito que debe acompañar al autor de obtener sentencia, resolución o acto administrativo contrario a la ley.

La Sala Penal de la Corte Suprema reiterando su posición ha sostenido 1. El tipo en cita, de acuerdo con su contenido, es de aquellos denominados de mera conducta, pues basta ejecutar el comportamiento, ya que debido a la potencialidad dañosa del acto del sujeto agente, el legislador ha determinado que debe ser objeto de sanción penal al margen del resultado obtenido.

Nos parece que la Sala Penal de la Corte Suprema en la sentencia citada, para afirmar qué tipo penal de fraude procesal es de mera conducta, supone que si este fuera un tipo penal de resultado, el resultado exigido para la plena tipicidad de la conducta sería la obtención de sentencia, resolución o acto administrativo ilícitos. En otros términos la decisión de la Sala Penal de la Corte Suprema se apresura a soportar su argumentación en la presencia del ingrediente subjetivo del tipo que exige constatar en el ánimo del agente - sin que para efectos de la consumación se requiera que el agente haya logrado su propósito, esto es, haber obtenido sentencia, resolución, o acto administrativo contrario a la ley.

En ese sentido debe precisarse que no todos los tipos penales con ingredientes subjetivos son tipos penales de mera conducta; existen tipos penales de resultado que también contienen ingrediente subjetivo, valga el ejemplo del tipo penal contentivo del delito de hurto (Código Penal Colombiano, Artículo 239. "El que se apodere de una cosa mueble ajena, con el propósito de obtener provecho para sí o para otro..."), en donde el legislador exige constatar el ánimo del sujeto agente de obtener provecho para sí o para otro.

El tipo penal contentivo del delito de hurto es indiscutiblemente un tipo penal de resultado, porque requiere en razón a la naturaleza del verbo rector utilizado por el legislador que el sujeto agente se apodere de la cosa mueble ajena. Se trata de un verbo rector de naturaleza transitiva que denota que la acción realizada -apoderarse- parta del sujeto y trasladándose sobre el objeto material del hurto que es la cosa mueble ajena. 
Como se trata de un tipo penal de resultado si el sujeto no logra apoderarse del objeto material responderá por tentativa del delito de hurto, por no haber logrado la tipicidad plena del delito.

Los ingredientes subjetivos son utilizados por el legislador para lograr precisar de manera certera la hipótesis típica, si no lo hiciera así sería típica de hurto por ejemplo la conducta de quien guarda el reloj de su amigo para que no se dañe o extravíe.

Pero en cualquier caso la necesaria constatación del ingrediente subjetivo no tiene nada que ver con el resultado típico. El ingrediente subjetivo está por fuera del tipo objetivo.

Nos parece que la definición de si se trata de un tipo penal de mera conducta o de resultado requiere algunas precisiones relativas al sujeto activo y al verbo rector del tipo penal contentivo del delito de fraude procesal.

Por razón del sujeto activo del tipo penal de fraude procesal sin discusión debe admitirse que se trata de un tipo penal monosubjetivo e indeterminado, en cuanto basta la presencia de una sola persona para su realización y el sujeto no requiere cualificación alguna para realizar su conducta.

Pero el tipo penal de fraude procesal tiene una característica muy especial pues es de aquellos que sólo pueden realizarse por un autor mediato; si se observa esta conducta delictiva, se advierte que no admite su realización por un autor directo con dominio total del hecho, sino que requiere la utilización instrumental del servidor público en quien el autor mediato debe lograr un estado mental de error, para que éste tome la decisión judicial o administrativa contraria a derecho que él desea.

En esas condiciones debe precisarse que el autor del delito de fraude siempre será un autor mediato que tiene el dominio de la voluntad de su instrumento el servidor público.

Esta precisión sobre la necesaria condición de autor mediato del sujeto activo del delito de fraude procesal, nos debe llevar a la conclusión que la conducta delictiva por él desarrollada implica la utilización de maniobras engañosas para lograr el estado errático en la mente del servidor público.

El autor mediato del delito de fraude procesal debe buscar un resultado y lograr un resultado típico que es obtener que el servidor público ingrese en un estado conceptual de error. 
Pero no se puede afirmar que siempre que se utilicen maniobras tendentes a lograr el error conceptual del servidor público se tenga éxito por parte del autor mediato, este puede fracasar en su intento de confundir al servidor público.

Quizás la confusión en la que incurre la Sala Penal de la Corte obedece a la forma en que el legislador reacciona frente a esta clase de delincuencia porque estima cumplido el delito cuando las maniobras fraudulentas son exitosas y logran obtener el estado mental de error en el servidor público, lo cual debe entenderse como el resultado típico requerido; ello es explicable por tratarse de un delito contra la Eficaz y Recta Impartición de Justicia.

En cambio si se trata de un delito contra el patrimonio económico individual, que eventualmente puede ser realizado por un autor mediato, la colocación en condición mental de error al instrumento, no consuma el delito, sino que requiere que el instrumento dominado en su voluntad por el hombre de atrás realice la actividad de apropiarse, por ejemplo, de una cosa mueble en el delito de hurto.

El ejemplo del hombre que estando en una cafetería, en el momento en que un lustrabotas culmina la limpieza de sus zapatos al pagarle la lustrada le pide el favor de que le lleve a su carro su maletín como si fuera suyo que está en una mesa cercana y que su dueño ha dejado allí para reservar su mesa mientras va al baño. Puede ocurrir que el lustrabotas colocado en el error mental por el autor mediato ejecute el acto consumando la apropiación al dejar el maletín en el carro del autor, o puede ser que en ese estado no lo logre porque en ese momento aparece el dueño, lo cual sería un delito tentado para el autor, o incluso puede ser que el autor ni siquiera logre inducirlo en error, pues el lustrabotas conoce al dueño del maletín y conoce el maletín y se niega a realizar la solicitud.

Si trasladamos este ejemplo al caso de fraude procesal, en las dos primeras hipótesis por haberse logrado el estado mental de error sería un delito consumado, en la tercera hipótesis sería un delito tentado.

En lo relativo al verbo rector recuérdese que el legislador al emplear la fórmula verbal se refiere en el tipo penal de fraude procesal a quien induzca en error a un servidor público, el verbo inducir es un verbo transitivo que denota que mediante maniobras más o menos sutiles, en este caso siempre fraudulentas, el agente logra impactar al servidor público haciéndolo caer en error. 
Del análisis del verbo rector es que surge diáfana la conducta típica que se reprocha, se reprocha al agente el inducir dolosamente en error al servidor público; es este un delito contra la eficaz y recta impartición de justicia, en el que el objeto material es el servidor público quien tiene que ser inducido en error.

La conducta desplegada por el autor mediato debe consistir en realizar maniobras fraudulentas, para dominar la voluntad y lograr con éxito que en la mente del servidor público surja un concepto equivocado de un asunto jurídico sobre el cual ha de resolver. -por ejemplo le presenta como soporte de una obligación clara, expresa y exigible en un pagaré falsificado- El error en el que el agente hace incurrir al servidor público es el resultado exigido en el tipo penal de fraude procesal y es indudable que existe una distancia temporal y espacial, entre la acción desplegada por el sujeto agente y el resultado consistente en obtener el estado errático en el servidor público.

El error en el que debe quedar el servidor público es un estado mental de aparente conformidad con la legalidad, estado en el que se encuentra como consecuencia del procedimiento de inducción al que ha sido sometido, cuando el procedimiento de inducción es exitoso; por el contrario, si el procedimiento de inducción no es exitoso quiere decir que el agente no logró su cometido a pesar de haber realizado actos ejecutivos inequívocamente dirigidos al logro del resultado típico que no es otro que la creación del error en la mente del servidor público.

Obsérvese que el legislador colombiano al redactar el tipo penal de fraude procesal no se refiere a quien por cualquier medio fraudulento trate de inducir en error, en tal caso estaríamos frente a un tipo penal de mera conducta, pero en la forma en que fue redactado el tipo penal el verbo rector denota una actividad cumplida, el logro de un resultado importantísimo para la lesión del bien jurídico de la justicia, cual es el lograr inducir en error al servidor público.

En esas condiciones es posible que el sujeto agente a pesar de utilizar cualquier medio fraudulento no logre el resultado de inducir en error al servidor público, quien pudo ser alertado por otro funcionario, o por un particular o un medio de comunicación sobre la treta fraudulenta, o el mismo funcionario en forma diligente evita el error, para citar algunas dentro de múltiples hipótesis, en tales casos estaríamos ante una tentativa de fraude procesal y no ante un delito consumado de fraude procesal. 
A la decisión de la Sala Penal de la Corte Suprema, de estimar que el tipo penal de fraude procesal es un tipo penal de mera conducta, le cabe como censura el no haberse detenido a estudiar las particularidades del sujeto activo de este delito, como tampoco realizó el análisis del verbo rector de esta conducta típica, lo cual la llevó a concluir que el acto de inducción se satisface mágicamente quizás con la solicitud del acto procesal o administrativo, que en ese sentido no se compadece con la naturaleza lógica de lo dicho por el legislador-El que por cualquier medio fraudulento induzca en error al servidor público-.

Por ello consideramos que el tipo penal contentivo del delito de fraude procesal es desde el punto de vista de su contenido un tipo penal de resultado porque exige lograr mediante inducción por medios fraudulentos el estado mental erróneo por parte del servidor público.

Otra cuestión es determinar cuándo se debe estimar que el servidor público se encuentra en situación de error, en nuestro concepto ello sólo se podrá determinar en cada caso en estudio, por ejemplo si lo que se propone es un proceso ejecutivo con un título valor que se ha confeccionado falsamente para ello, pensaríamos que cuando el Juez libra el mandamiento ejecutivo se puede considerar evidenciado el estado de error en el que ha sido inducido exitosamente, por lo que con el logro del resultado se puede considerar realizada la tipicidad plena de la conducta de fraude procesal.

b. Es Tipo Penal de Fraude Procesal un Tipo de ejecución instantánea, de Conducta Permanente o de estado.

La doctrina penal teniendo en cuenta el tiempo de ejecución de la conducta típica, distingue entre delitos de conducta permanente, delitos de estado y delitos instantáneos, "según que la actividad o el resultado determinen la aparición de un estado antijurídico de cierta duración (delitos permanentes y delitos de estado) o no (delitos instantáneos). (MIR PUIG, 2002, página 202).

\section{-Tipos Penales de Conducta Instantánea.}

Los tipos penales instantáneos se caracterizan porque con la realización del comportamiento descrito o la producción del resultado requerido se agota en su totalidad la hipótesis típica, sin que ello determine una situación antijurídica duradera. 
Ejemplo de los tipos penales de conducta instantánea la encontramos en el homicidio en el que el resultado muerte consuma en su totalidad la conducta delictiva.

Este agotamiento típico permite empezar a contabilizar el término prescriptivo de la acción a partir de la consumación del resultado muerte. (Artículo 84, inciso primero, Código Penal colombiano).

\section{-Tipos Penales de Conducta Permanente.}

Son tipos penales de conducta permanente aquellos en los que-el delito no está concluido con la realización del tipo, sino que se mantiene por la voluntad delictiva del autor tanto tiempo mientras subsista el estado antijurídico creado por el mismo. (ROXIN, 1997).

El secuestro (Articulo 168, código Penal colombiano) es un delito de conducta permanente, ello se explica porque si bien su realización típica se consuma con la privación de libertad a la que el secuestrador somete a su víctima, su carácter permanente deviene de la reiterada renovación de la conducta por parte del agente, manteniéndose la situación antijurídica durante el tiempo en el que mantiene con dominio del hecho la privación de la libertad de su víctima.

Esta característica de los delitos de conducta permanente hace que la prescripción de la acción se empiece a contabilizar a partir del último acto realizado (Artículo 84, código Penal colombiano).

\section{-Tipos penales de estado.}

Esta distinción, como lo explica acertadamente Mir Puig, entre los delitos de conducta permanente y delitos de estado proviene de la doctrina alemana en consideración a que si bien existen conductas delictivas que crean un estado antijurídico duradero, la consumación cesa desde la aparición de éste, porque el tipo sólo describe la producción del estado y no su mantenimiento. (MIR PUIG, 2002, p. 202).

En palabras de Maurach, "Mientras que el autor del delito de estado se desprende de su hecho con la consumación, el del delito permanente... omite poner término a la situación creada.” (MAURACH, 1968, p. 427).

Sirven de ejemplo para identificar los delitos de estado las conductas de bigamia o matrimonio ilegal- que ya no son típicas en nuestro derecho- 
en los que el autor una vez cumplido el hecho deja de ocuparse de él, puesto que no requiere la renovación permanente del mismo con ejercicio del dominio del hecho.

Sin que pueda ignorarse que el resultado antijurídico permanece, ocurre entonces lo que el profesor Mir Puig señala como característica de estos tipos penales, que su consumación cesa desde la aparición del estado antijurídico duradero, porque el tipo sólo describe la producción del estado y no su mantenimiento.

Jescheck (2002, p. 281) contempla los tipos penales de estado junto con los tipos penales de conducta permanente como unas subcategorías de los tipos penales de resultado en los que su efecto permanece durante un cierto espacio de tiempo, siendo la diferencia que en los delitos de conducta permanente la situación antijurídica creada por la acción punible depende de la voluntad del sujeto activo renovándose la conducta; en tanto en los delitos de estado se tiene una situación antijurídica que se ve consumada con el último acto, a lo que trae como ejemplo tipos de usurpación del estado civil, la bigamia y los daños materiales.

La distinción entre los tipos penales de conducta permanente y tipos de estado es trascendente para el estudio que realizamos porque conforme a lo señalado el tipo penal de fraude procesal se nos revela como un tipo penal de estado, en el que su consumación se cumple con la colocación en estado de error al funcionario público, sin que el legislador le exija al autor con dominio del hecho el mantenimiento en el error al funcionario.

Además recuérdese que el ingrediente subjetivo contenido en el tipo penal de fraude procesal -el propósito de obtener sentencia, resolución o acto administrativo ilícitos- su logro no hace parte del tipo objetivo del delito de fraude ni se requiere la consumación de este ilícito.

La correcta hermenéutica de los tipos penales de estado nos indica que deben regirse por las reglas de los tipos penales de ejecución instantánea en lo que tiene que ver con su momento consumativo y el momento en que debe iniciarse el tiempo de prescripción de la acción penal.

\section{CONCLUSIONES}

Del análisis dogmático y jurisprudencial del tipo penal de fraude procesal es manifiesta la contradicción que surge en las decisiones de la 
Corte Suprema de Justicia frente a los contenidos teóricos de la tipicidad para la interpretación y aplicación del tipo penal de fraude procesal, en tanto siguiendo el estudio lógico de la tipicidad queda demostrado que este es un tipo penal de resultado consistente en la inducción en error al servidor público y no de mera conducta como la ha sostenido la Corte.

Por otra parte tampoco se puede predicar que el tipo contentivo del delito de fraude procesal sea de conducta permanente porque el autor carece de dominio de la voluntad sobre la permanencia del tipo penal, siendo entonces un delito de estado en la que el resultado previsto en el tipo penal crea una situación jurídica o fáctica ilícita pero se entiende dicha situación como agotamiento del delito posterior a su realización, ejemplo de ello para Jescheck (2002, ibídem) son los tipos de usurpación del estado civil, la bigamia y los daños materiales.

Los tipos penales de estado comparten las reglas de aplicación con los tipos de ejecución instantánea, en todo caso, aunque los tipos de estado no han tenido una acogida en la dogmática penal nacional, y de tenerse estos por excluidos, es necesario considerar el tipo penal de fraude procesal como de ejecución instantánea.

La diferencia que se observa entre el análisis teórico del tipo penal y la aplicación de la Corte Suprema de Justicia es más que una simple divergencia jurídica de criterio, que tiene profundas consecuencias en las garantías de los ciudadanos y enflaquece la consecución de los fines constitucionales del derecho penal.

Al tipo penal le es inherente una función garantista de cara a las personas que les permite conocer las prohibiciones y mandatos penales para motivar su conducta en una dirección que no le acarrea sanciones penales, así como concede a los ciudadanos el derecho de no ser juzgados penalmente por conductas distintas a las contempladas en la ley.

Así que es evidente que la aplicación de la Corte vulnera estas garantías de las que vale señalar la prescripción de la acción penal, la tentativa, el desistimiento y el derecho penal de acto con el que debe contar todo autor de un injusto penal; todas garantías emanadas de la tipicidad como estructura dogmática del delito.

Como pudo observarse del recuento jurisprudencial, el criterio de la Corte atenta directamente contra la garantía de la prescripción de la acción porque al considerar el tipo penal de fraude procesal de ejecución 
permanente al punto de no entender terminada la conducta hasta que los efectos de la misma hayan desaparecido del mundo jurídico, hacen que el delito se convierta en imprescriptible porque la prolongación de los efectos de la conducta dependen de procesos administrativos o judiciales que pueden tardar años hasta su culminación, o que pueden no culminar nunca ante un delincuente exitoso; teniendo entonces un sujeto activo que a pesar de no desplegar ninguna acción y cesar en su conducta incurre en la vulneración a una prohibición penal con efectos sobre su derecho a la prescripción del tipo penal.

La tentativa como dispositivo amplificador del tipo en el que la conducta punible no logra su consumación fundamenta la disminución punitiva en la menor afectación del bien jurídico, la interpretación de la Corte también arrasa con este derecho en cabeza de quien inicie una conducta de fraude procesal pero no logre el resultado típico por motivos ajenos a su voluntad, porque al tratarse como un delito de mera conducta sin serlo, no es conceptualmente posible imputar la tentativa, excluyendo la menor punibilidad y sometiendo a un ciudadano a una sanción penal superior a la que dicta el ordenamiento jurídico.

En congruencia con lo anterior, otro derecho que se ve desaparecido al considerar erradamente el delito de fraude procesal como de mera conducta, es la posibilidad que tiene el sujeto activo de desistir de la conducta punible, posibilidad cercenada a quien inicie la conducta punible presentando medios fraudulentos ante la autoridad, pero posteriormente dirige su actuar a evitar el resultado y efectivamente lo consigue.

Así, con la interpretación de la Corte el sujeto agente no podrá desistir en la conducta punible a pesar de que el servidor público no haya aún tenido acceso alguno a los medios fraudulentos y el sujeto activo realice todas las actividades necesarias para evitar la ocurrencia del resultado típico.

Otra garantía desconocida por el criterio de la Corte Suprema de Justicia es la relativa al derecho penal de acto que para el asunto en estudio se explica a partir de la teoría del dominio del hecho, la cual implica que el autor de un delito para que sea tal, debe estar en la posibilidad de iniciar voluntariamente su ejecución y así mismo poder detenerla, esto supone que el autor de la conducta va a responder sólo por la conducta que voluntariamente despliegue.

La interpretación de la Corte destierra esta garantía porque el autor una vez inicia su conducta o induce al servidor público en error tiene responsabilidad 
penal por hechos que escapan a su control voluntario y funcional, retornando a una suerte de casualismo en la que la persona responde por hechos y actuaciones estatales de las que no tiene participación.

Ejemplo de ello es quien presenta una demanda civil espuria, una vez inducido en error al juez, el autor no podrá detener su conducta hasta que el respectivo juez civil haya terminado el proceso, respondiendo el sujeto agente hasta que el funcionario inducido en error haya procesado mediante actuaciones el error y excluido del mundo jurídico el acto o providencia propósito del delito y no contándose la prescripción de la acción penal hasta que tal suceso ocurra.

Desde esta perspectiva queda plenamente evidenciada la posición sostenida y errática de la Corte Suprema y las graves consecuencias que siguen afrontando los colombianos sometidos a procesos penales por la comisión del tipo en cuestión.

\section{REFERENCIAS BIBLIOGRÁFICAS}

Jescheck, H. (2002). Tratado de Derecho Penal Parte General, Granada, Quinta edición

Maurach, R. (1962). Tratado de Derecho Penal, Tomo II, Barcelona, Ariel

Mir Puig, S. (2002) Derecho Penal Parte General, Barcelona, Corregrafic. S.L. Quinta reimpresión

Reyes, A. (1981). La Tipicidad., Bogotá, Colombia, Universidad Externado de Colombia, Quinta edición

ROXIN, C. (1997). Derecho Penal. Parte general. Tomo I, CIVITAS 